\title{
A CONTRIBUTION TO THE PATHOLOGY OF IDENTICAL TWINS
}

\author{
BY
}

CORNELIA DE LANGE

(From the Department of Paediatrics, University of Amsterdam.)

It must first be stated that the diagnosis of the type of twinning in each of the cases here described was made by a midwife, the women being delivered at their own homes and not in hospital. There is still controversy about the best method of diagnosis and Reichle ${ }^{1}$ is of opinion that even reports of membrane examination are valueless unless they describe the condition of the septum. In monochorionic twins the septum should be composed of amnion only. It was not possible in the present cases to gain any information about the septa, but all three midwives have been certain that there was only one placenta and one chorion. It is well known that Siemens's method ${ }^{2}$ is unreliable when applied to infants and young children in as much as congenitally determined characteristics may have a delayed manifestation; this especially holds true for the colour of the iris.

I myself am fully convinced that these three sets of twins are really monozygotic, their similarity being so striking.

\section{Case record-first pair.}

C. F., born 22.7.1921, was sent to the Hospital for Sick Children in Amsterdam on account of pyloric stenosis and was there under my care from October 22 till December 24, 1921. The child received medical treatment, left almost cured and developed in a normal way. Afterwards she became maternal aunt to the twins $\mathbf{H}$ and K. These children, boys, were born on January 30, 1935, six weeks before term. $\mathbf{H}$ was born as a breech presentation, weighing 2,570 gm. He was not asphyxiated. $\mathrm{K}$ weighed $2,650 \mathrm{gm}$. and was slightly asphyxiated but soon developed a normal colour. Both children were breast fed and at first all went well, the children steadily increasing in weight. On February 26 projectile vomiting abruptly set in with $\mathbf{H}$. The weight continued to increase with two interruptions till March 3, when a considerable drop was noted. $\mathrm{K}$ began forcible vomiting on February 27. At first he continued to gain weight but later there was a slow and then a rapid fall in weight. The children were admitted to the clinic on the evening of March 4 and on the following morning the weight of $\mathrm{H}$ was $2,770 \mathrm{gm}$. (length $47 \mathrm{~cm}$.) and that of $\mathbf{K}$ 2,550 gm. (length $49 \mathrm{~cm}$.) (fig. 1).

As medical treatment was of no avail Rammstedt's operation was performed in both cases by the late Professor O. Lanz on March 11, the weight of $H$ being then 2,610, that of $K 2,490 \mathrm{gm}$. Both children presented the typical olive-shaped pyloric tumour, 
that of $\mathbf{K}$ being somewhat larger than that of $\mathbf{H}$. The immediate effect of the operation on the general condition was quite remarkable. The children who before had been ill at ease, fretful and drowsy with a tense facial expression, went peacefully and happily to sleep and awoke in an altered condition. The evening temperature of $\mathbf{H}$ was normal; in $\mathbf{K}$ there was a slight rise*.

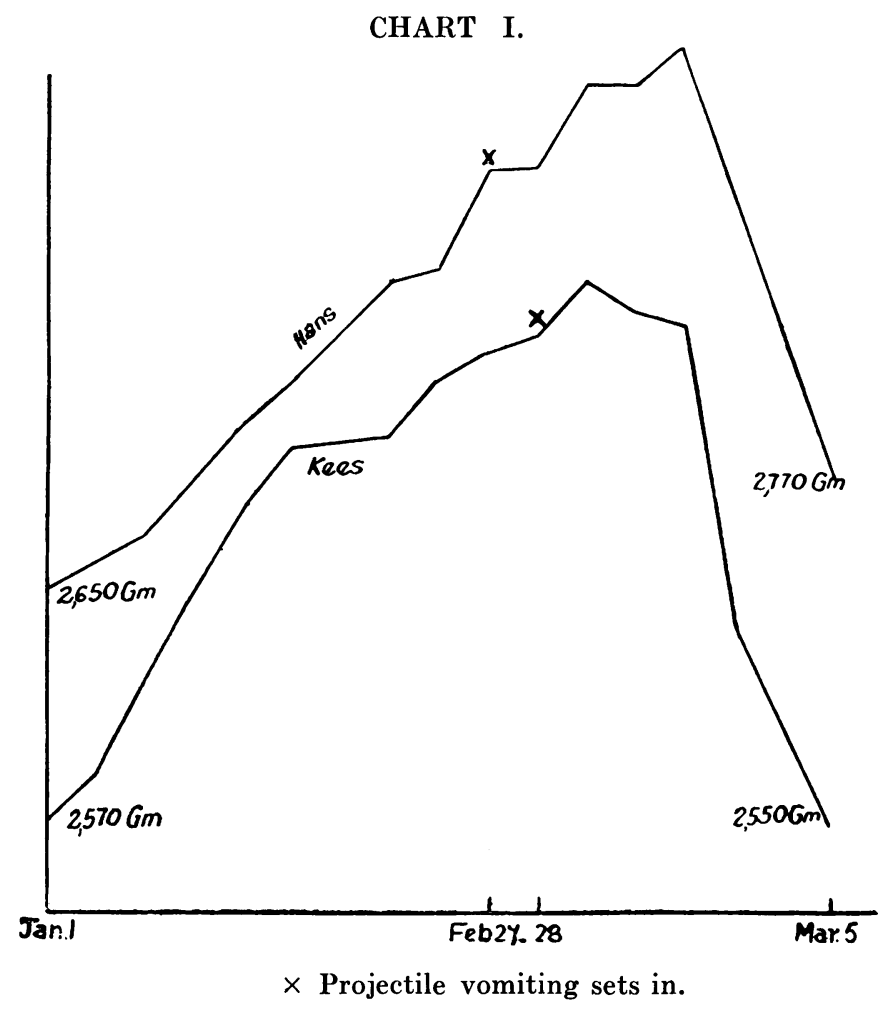

The course in $\mathbf{K}$ ran quite uneventfully. The mother came to the clinic to feed her children and as a supplementary food, buttermilk with flour and sugar was given after the well-known formula. On leaving the clinic on April $10 \mathrm{~K}$ weighed 3,700 gm.

With $\mathbf{H}$ there was some trouble; he developed diarrhoea and only progressed slowly, but after some time all went well and he left hospital on the same day as his brother, weighing $3,710 \mathrm{gm}$. their weights being now practically equal.

\section{Similar cases.}

Pyloric stenosis as a concordant sympton in monozygotic twins has been observed by Varden ${ }^{3}$ (boys; vomiting setting in a month after birth, no peristalic waves but typical pyloric tumour found on operation.) The same

* According to L. F. Meyer and E. Nassau (Die Säuglingsernährung, 1930) there is almost always a fever of unknown origin in the evening after the Rammstedt operation. In my own experience this fever is often absent. 
author had a personal communication from Moore and Bilderback ${ }^{4}$ that their cases also occurred in monozygotic twin boys. Sommer's observation ${ }^{5}$ is interesting, as the monozygotic twins were girls. In one the vomiting set in on the twelfth day after birth, in the other one on the eleventh.

From the point of view of heredity the fact that the maternal aunt also suffered from the same illness adds special interest to the present observation.

In the fourth of his interesting experiments on identical twins with unboiled and boiled breast-milk respectively, Bernheim-Karrer ${ }^{6}$ mentions without further details that both children had forcible vomiting (not real pyloric stenosis as he emphatically states), but with one of the twins the vomiting was much less than with the other. This marked difference in identical twins is noteworthy, but, as the author says himself, it might be possible that the boiling of the milk in causing a thickening of the fluid, had worked as a therapeutic measure. Lasch $^{7}$ reports the following case :-

Diagnosis of monozygotic twinning was made in the Obstetrical Clinic of the University of Breslau on account of monochoria. There was also a striking similarity of pigments of iris and hair and of the shape of the head. At the end of the third week in one of the children, who were both breast fed, the symptomatology of pyloric stenosis set in. Operation was considered, but an influenzal infection proved fatal. Post-mortem examination confirmed the diagnosis. The other twin never presented symptoms of pyloric stenosis.

Bernheim-Karrer in discussing this case is not wholly disinclined to doubt the identity of the twins. However, Lasch does not leave much room for doubt, but expresses himself guardedly as to the conclusion to which his observation entitles him. Before stating that heredity plays no part and that parakinetic factors are responsible, he claims the necessity of a larger number of observations, as in exceptional cases an unequal distribution of factors during cleavage may take place, or an 'idiokinesis' in utero or a marked variability of the heredity factors ('Erbanlage ') may be present.

\section{Discussion.}

Before they were operated upon and also when they were five-and-a-half months old I studied these twins. It is well known that in so-called congenital pyloric stenosis the symptoms do not begin at birth, but only after a lapse of time. In the records of our clinic the longest duration was five weeks, but in the medical literature still longer periods are mentioned. All authors agree that it is not the stenosis but the supervening spasm which causes the peristalsis and the forcible vomiting. It is therefore pertinent to ask what is the underlying cause of the spasm? Some attribute it to a nutritional disorder of the child, others to a defect in general care, but in the present instance the children were well fed and well cared for. They showed not a single intestinal or other trouble before the spasm set in. Another cause, probably intrinsic must be looked for and it is tempting to think of the hormonal influences. Having hitherto kept one another in balance, 
one now begins to predominate. The second step is to presume the dominant hormones originate from the mother's milk or the mother's placenta. The hereditary factor then shows itself in the fact that the twins' grandmother, has produced a hormonal spasm in the pylorus of her other daughter, the maternal aunt to the twins. Although this is a speculative hypothesis, it is clear that no extrinsic influence can be made responsible for the beginning of the spasm in both children almost on the same day.

Boys (80-85 per cent.) are much more frequently affected than girls; this fact has lead Stolte ${ }^{8}$ to the hypothesis that the hormones which in pregnancy establish the growth of the uterus of the mother, after being transmitted by the placenta or by the milk of the mother to the child, are responsible in newborn girls for the relatively large size of the uterus and in newborn boys they affect another muscular organ, the pylorus. Children with pyloric stenosis (spasm) almost always have nervous, ' neuropathic' parents and themselves often exhibit other symptoms of neuropathy.

That the hypertrophy of the pylorus is secondary to 'overwork' ('Arbeitshypertrophie') brought about during intra-uterine life by a developmental neurosis seems highly probable. The paternal element in its origin can then also come in. I once saw a family where five children were affected with pyloric stenosis and several cases are mentioned in literature where more than one child suffered from it in the same family. In one of Feer's observations two children in one family had pyloric stenosis and it was proved that a child in another family who also was affected, had the same great-grandfather as those two children. Tj. Halbertsma ${ }^{9}$, of Haarlem, has recently given an interesting pedigree concerning the heredity of the disease.

$\mathbf{H}$ and $\mathbf{K}$ while staying in the clinic presented a striking similarity, but yet showed some differences. $K$ had a pale naevus on the neck and one on the glabella; $\mathbf{H}$ had one on the neck only. Pale naevi in those places are almost of normal occurrence and have a tendency to disappear. So it is possible that the one on the glabella of $\mathbf{H}$ had already disappeared. There was some difference in the shape of the ears in each child. The right ear of $\mathbf{H}$ and the left of $\mathrm{K}$ having part of the border unfolded and the left ear of $\mathbf{H}$ and the right of $\mathbf{K}$ showing a broad lobule. This mirrorimage effect is characteristic of monozygotic twins, but is not necessarily present. The feet of $\mathbf{K}$ had the plantar lines called by Brushfield ${ }^{10}$ 'A' (oblique plantar line), ' $B$ ' (transverse plantar line) and ' $C$ ' (transverse hallucial line). The left foot of $\mathbf{H}$ also showed these lines, but his right foot showed a deep oblique plantar line running to the mesial footborder, the transverse hallucial line not being clearly marked. An interesting fact is that $K$ presented some symptoms of the exudative diathesis in the form of small papules in the face and that his stools were often greenish with small white particles, not amounting to diarrhoea and with steadily increasing weight. This was quite different from the frequent stools of $\mathbf{H}$ during part of his stay in hospital. 
The children were re-examined at the age of five-and-a-half months. Their progress had been quite satisfactory (fig. 1). Leaving the hospital with practically the same weight. $\mathbf{H}$, who had been heavier at birth, was now left behind. A month after their discharge $\mathrm{H}$ weighed 4,500 gm., K 5,050 gm.; from then onwards their weight curves run almost parallel, as is seen in chart 2 .

$\mathrm{K}$

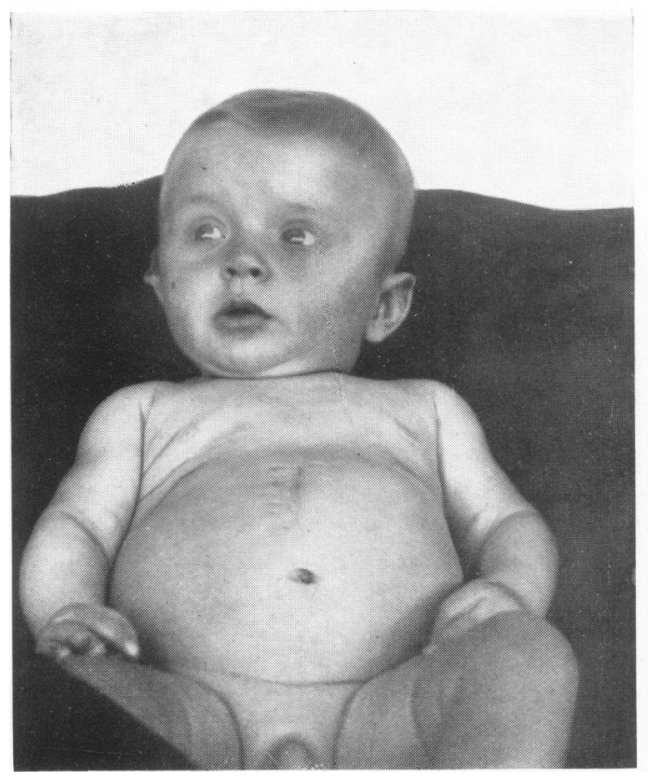

H.

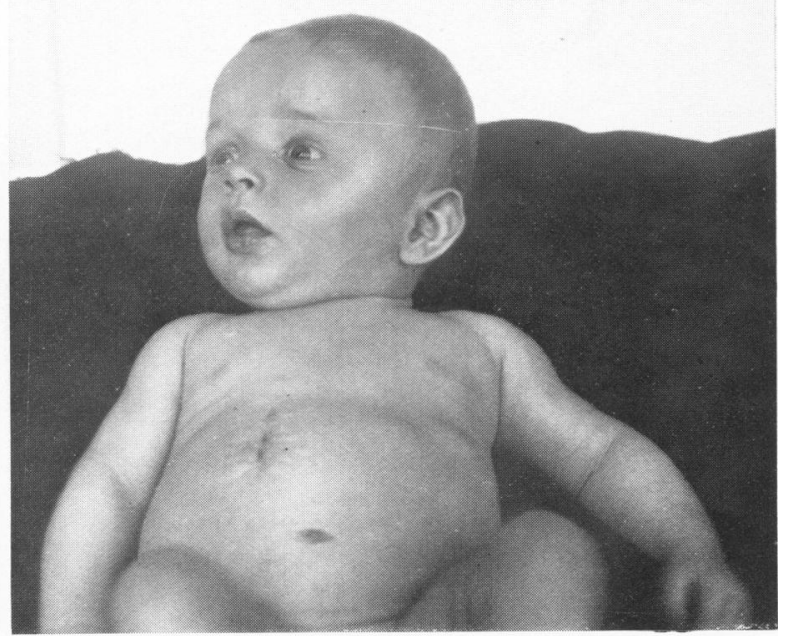

FIc. 1.-Both twins showing operation scars.

Age $\mathbf{5}_{2}^{1}$ months.

SUMmary of EXaMination at THE age OF FIVE-AND-A-HaLf months.

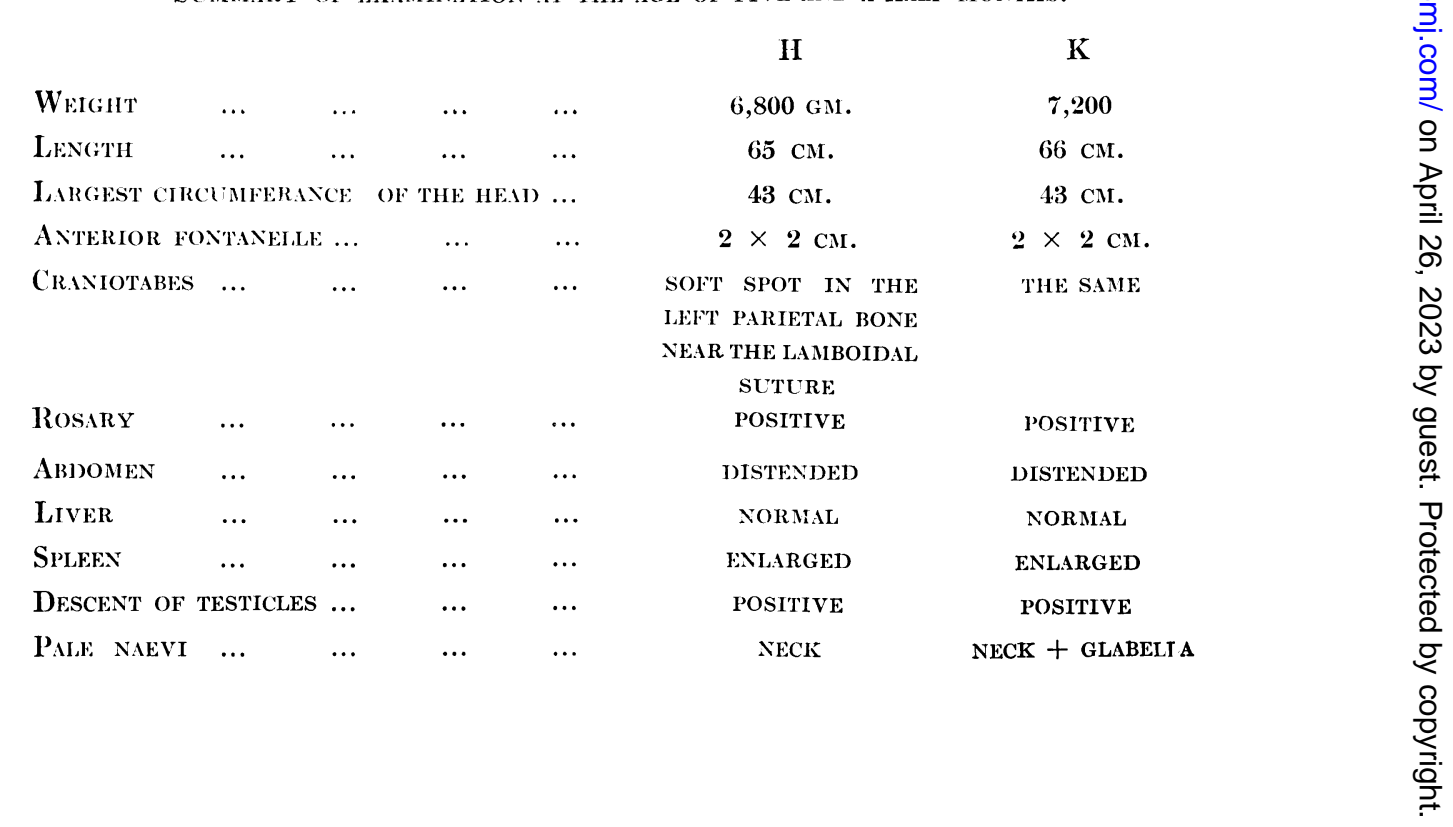


Both children appeared to be of normal intelligence. Their digestion was good; they did not show symptoms of the exudative diathesis. Their development appeared approximately normal. They were of a friendly disposition, laughing readily, but they were nervous and started at every sound. It is interesting to note that $\mathbf{H}$ loathed stewed apples and $\mathbf{K}$ had a preference for this fruit.

\section{CHART II.}

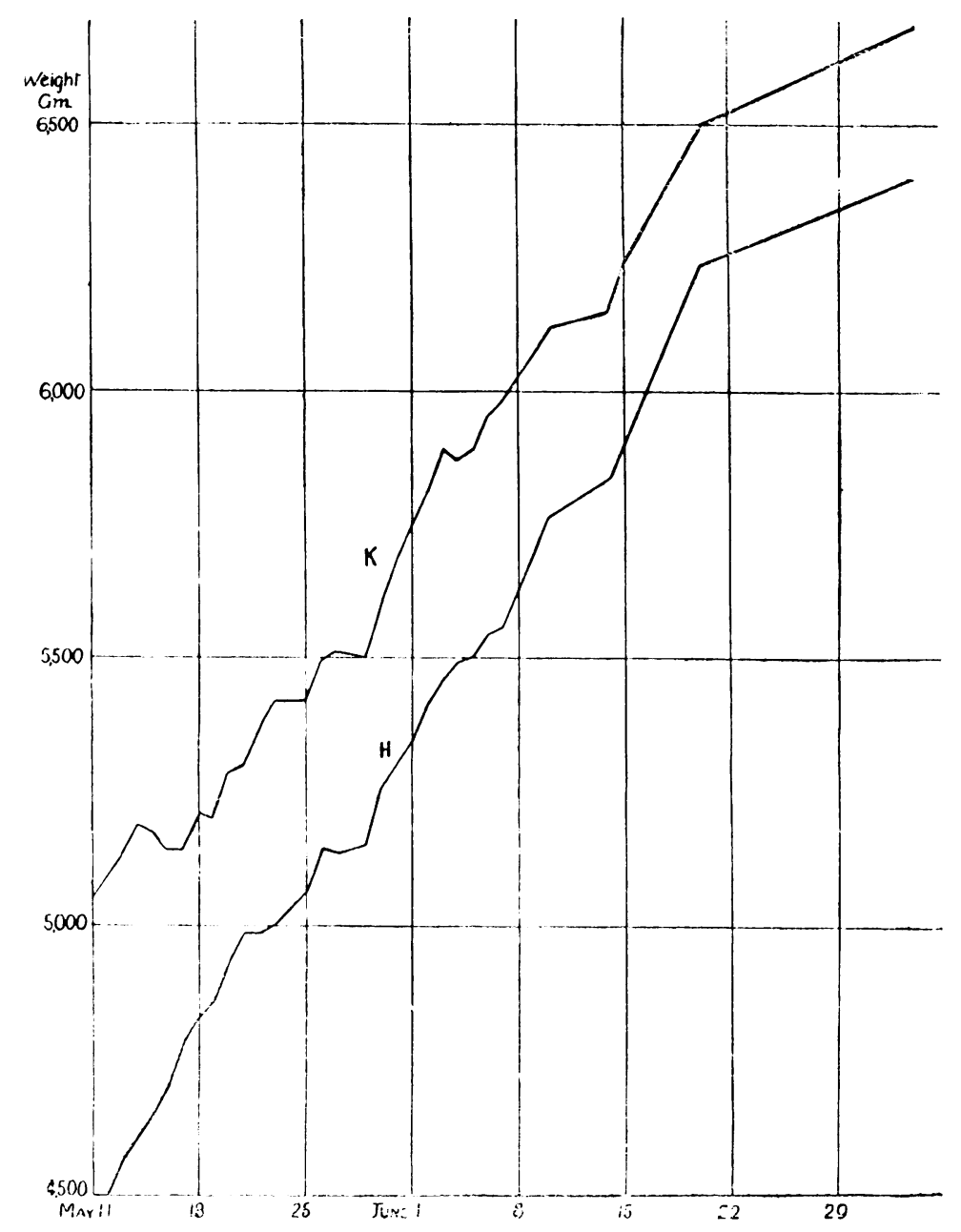

It will be seen from the summary of this examination that the children are in good health, but have developed rickets in exactly the same way. They were premature infants and rickets is widespread in Amsterdam. The fact that $\mathbf{H}$ did not develop any more symptoms of the exudative diathesis is interesting as also that they were still lacking in $\mathbf{K}$. 
That identical twins may show small differences in their somatic habitus, without the diagnosis of monozygotic twinning having to be rejected, is generally agreed upon.

Orgler $^{11}$ established discordancy in nine out of fourteen identical pairs of twins. This large number may perhaps be explained, says the author, by the fact that young infants are in the most labile period of the whole of human life and that the heritage (' Erbgut') may be altered by external stimuli, which afterwards will have no appreciable effect. It is well known that in identical twins the similarity increases as the persons grow older (see for instance the portraits in the article of Weitz mentioned below), whilst in dizygotic twins the likeness becomes less. In three of the pairs of twins which came under Orgler's observation the exudative diathesis ran quite different courses in one of the twins from that in the other one.

\section{Case record-second pair.}

The child F, boy, born November 11, 1934, was brought to the Clinic on April 13, 1935, for a right-sided, strangulated inguinal (scrotal) hernia. Both this child and his identical twin-brother, also called F, had within the first month of their lives developed bilateral scrotal hernias. In general the four hernias were unreduced as is shown in fig. 2, the children being quite happy in this state

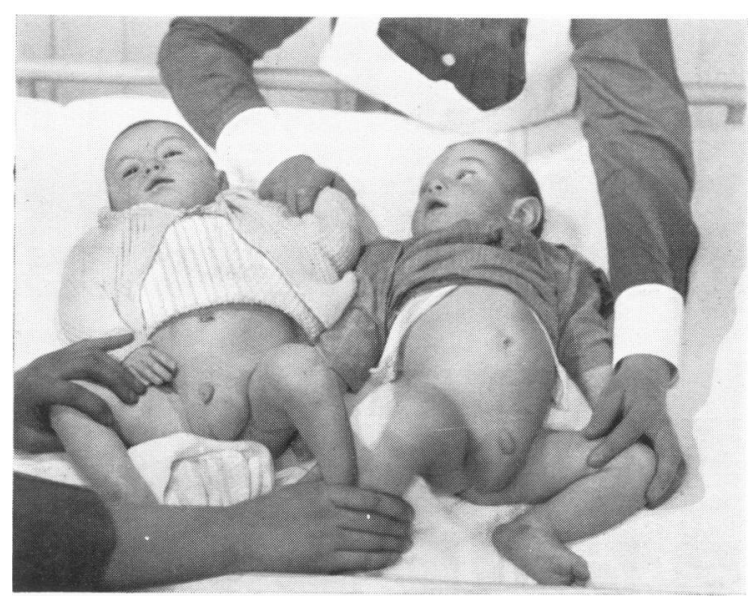

FIg. 2.-Twins F., age $5 \frac{1}{2}$ months. Bilateral scrotal hernia in both twins.

according to the mother. In one of the boys the right half of the scrotum had become tender, swollen and of a bluish hue. The hernia then proved irreducible. In the Clinic the child was placed in his cot in a Trendelenburg position and an icebag applied to the swelling. In the course of a few hours the intestine could be returned to the abdominal cavity. Later the child was operated upon.

Some authors are of opinion that the cause of hernia lies for the greater part in extrinsic conditions. Siemens in his ' $Z$ willingspathologie' mentions 'M3 $+\phi$ ' (i.e. in three monozygotic twin pairs only one child had the 
hernia, the other being free from it). Versluys ${ }^{12}$ put it as ' $\mathbf{M} 2+\phi$,' but Weitz $^{13}$ found unilateral inguinal hernia ' $\mathbf{M} \mathbf{2}++^{\prime}$ ' and umbilical hernia ' $\mathbf{M} 1++$.'

In recent years more facts have come to light and Luxenburger ${ }^{14}$, who sums up the material, says: " The heredity of the syndrome of feebleness of the connective tissue, which manifests itself amongst others in the tendency to pes cavus and pes planus and to hernia and constitutes a real stigma of the asthenic type of bodybuild, has been corroborated by the study of twins.'

In the literature I could find only one observation of bilateral hernia in identical twins (Hanrart quoted by Siemens) but as the original publication could not be consulted, further particulars cannot be given. As far as I know an observation of bilateral inguinal hernia developing so soon after birth, has not previously been published. Stransky ${ }^{15}$ records the following most interesting case history:-

Identical twins, boys, birth weight about $1,000 \mathrm{gm}$. were admitted to the hospital, aged two-and-a-half months. Their weight then was about $3,000 \mathrm{gm}$. Both had open inguinal rings but no hernia. On the fifth day after their admission both children went into convulsions of unknown origin, both developed a strangulated hernia and died after a few hours. At a post-mortem examination it was found in one twin that at the extreme end of the ileum a Littré hernia, about the size of the terminal phalanx of a finger, was strangulated in the left much enlarged, inguinal canal. Swelling and haemorrhagic infarction of testicle and epididymis was present together with thrombosis of the pampiniform plexus. In the other twin an open inguinal canal was present on the right side with haemorrhagic infarction of right testicle and epididymis and thrombosis of the pampiniform plexus.

\section{Case record-third pair.}

The child W born on July 17, 1934, was transferred to the Clinic on March 11, 1935, from one of the surgical wards, where she had been admitted on account of an acute glandular swelling at the angle of the jaw. W is the second of twin-girls. Both children were full-time babies, born spontaneously as head presentations. They were not asphyxiated. The weight of $W$ was about $2,500 \mathrm{gm}$. and of her sister $\mathbf{E}$ about 3,500 gm. They were breast fed during the first month, then had buttermilk, after that milk and water with flour and sugar, and then mixed diet.

The twins are strikingly alike, according to the mother. Both had the rare combination of dark eyes and blonde hair (fig. 3). Even at birth W had already a natiform skull. On admission her weight was $6,730 \mathrm{gm}$. (at eight months), length $66 \mathrm{~cm}$. There was only a mild degree of rickets present according to the x-ray pictures and blood-chemistry (Ca 11.2 mgm. per cent., P $4.9 \mathrm{mgm}$. per cent.). The largest circumference of the head was $46 \mathrm{~cm}$., biparietal dimension $25 \mathrm{~cm}$. There was a high forehead with marked bossing of the frontal eminences and somewhat less of the parietal ones. One small soft spot in the occiput was felt. The anterior fontanelle measured $7 \times 6 \mathrm{~cm}$., and was bulging with firm borders. Teeth were absent. There was no rosary and no 
enlargement of the epipyses. The liver was not enlarged, the spleen was palpable, and there was slight divarication of the abdominal rectus muscles. Lumbar puncture showed pressure $32 \mathrm{~cm}$., normal fluid, including microscopic examination. The Wassermann and Sachs-Georgi reactions in the blood were negative. After the lumbar puncture the tension of the anterior fontanelle has somewhat lessened.

During the child's stay in the hospital the mother was asked to bring the other twin for inspection. The clinical picture was the same. Rickets was present to a mild degree. The natiform

$$
\text { E. W. }
$$

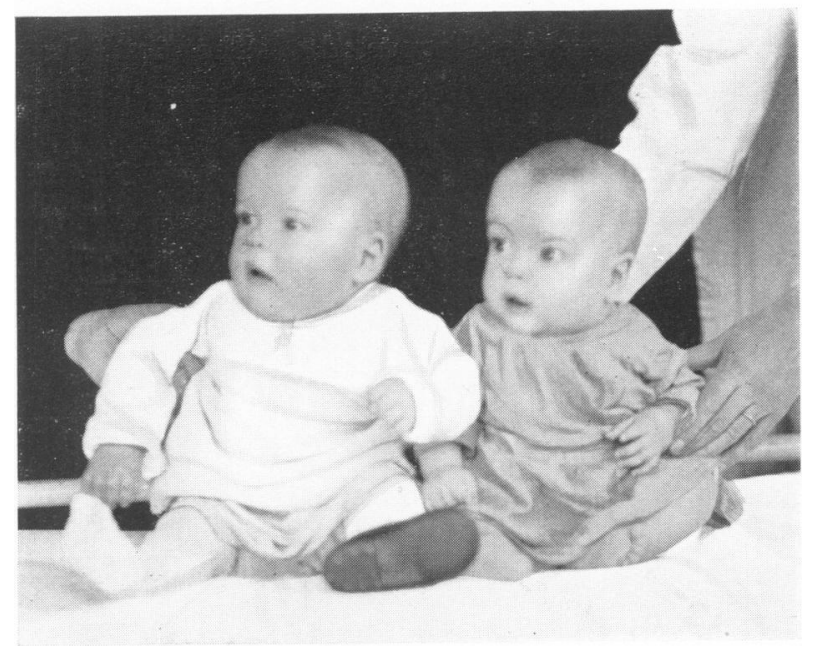

FIG. 3.-Twins W. and E., age 8 months.

shape of the head was also present, but less pronounced, so that it could be readily understood why the mother spoke of the peculiar head of $\mathbf{W}$ and not of $\mathbf{E}$. The largest circumference of the latter's head was $45 \mathrm{~cm}$., the biparietal dimension $25 \mathrm{~cm}$. The anterior fontanelle measured $7 \times 6 \mathrm{~cm}$., and also showed increased tension. A lumbar puncture was not feasible in the circumstances.

What is the underlying cause for the shape of the head and the increased pressure of the cerebrospinal fluid in these twins? Rickets, syphilis and prematurity may be left aside, the first because the natiform skull was already present at birth. Hydrocephalus generally produces a different shape to the head, yet the symptoms of the children can only be interpreted as caused by hydrocephalus. I believe that they have hydrocephalus, but the congenital anomaly which gives rise to the obstruction in the circulation of the fluid must of necessity be of little importance, otherwise the size of their heads would have been much larger. Perhaps already a fluid-balance has been established. It cannot be decided finally whether the shape of 
head is dependent on the hydrocephalus or is an anomaly in itself. The fact that the natiform skull was more marked in $\mathbf{W}$ than in $\mathbf{E}$ can perhaps be explained by the influence of factors during intra-uterine life or during delivery.

\section{Summary.}

The study of identical twins has proved to be of the utmost value in separating the influences of heredity from those of environment. If clinicians make it a rule to observe and carefully follow up monozygotic and the dizygotic twins in their practice, they may render valuable services to science.

Three observations are here reported. The first describes pyloric stenosis in monozygotic twins and in their maternal aunt. The second shows inherited weakness of the connective tissue by the almost simultaneous appearance of bilateral inguinal hernias in identical twins. The third deals with mono-ovular twins, both with a natiform skull without any relation to prematurity, syphilis or rickets and also with a mild degree of hydrocephalus.

\section{REFERENGES.}

1. Reichle, H. S., Biol. Bull., Woods Hole, 1929, LVI, 164.

2. Siemens, H. W., Die Zwillingspathologie, Berlin, 1924.

3. Varden, A. E., J. Pediat., St. Louis, 1933, III, 493.

4. Moore \& Bilderbach quoted by Varden.

5. Sommer, R., Deutsche Ztschr. f. Chir., Berlin, 1931, CCXXXII, 398.

6. Bernheim-Karrer, J., Ztschr. f. Kinderh., Berlin, 1929, XLVII, 427.

$\therefore$ Lasch, W., München. med. Wchnschr., Munich, 1925, LXXII, 1155.

8. Stolte, K., Deutsche med. Wchnschr., Leipzig, 1929, II, 2007.

9. Halbertsma, Tj. Maandschr. v. kindergeneesk, Leyden, 1935, V, 24.

10. Brushfield, T., Brit. J. Child. Dis., London, 1925, XXII, 274.

11. Orgler, A., Med. Klin., Berlin, 1935, XXXI, 541.

12. Versluys, J. J., Thesis, Amsterdam, 1928.

13. Weitz, W., Ztschr. f. klin. Med., Berlin, 1925, C, 115.

14. Luxemburger, H., Ztschr. f. indukt. Abstammungs-u. Vererbungsl., I,eipzig, 61.

15. Stransky, E., Monatschr. f. Kinderh., Berlin, 1926, XXXI, 613. 